\title{
Budaya dan Sistem Kekeluargaan Etnis Aneuk Jamee: Studi Kasus di Aceh Selatan
}

\author{
Julianti Sahputri \\ Universitas Sumatera Utara \\ juliantisahputri45@gmail.com \\ Budi Agustono \\ Universitas Sumatera Utara \\ agustono_budi@yahoo.com \\ Fikarwin Zuska \\ Universitas Sumatera Utara \\ fikarwin.zuska@gmail.com
}

\begin{abstract}
The Aneuk Jamee tribe is an acculturation of the Acehnese and Minangkabau tribes, both of which seem to have merged into one individual to produce a new ethnicity. This ethnicity later developed in South Aceh and influenced various aspects of culture and the family system in it. This research is classified as field research with a qualitative approach. The methodology used is phenomenology which is supported by historical literacy in the South Aceh region where the Aneuk Jamee ethnicity is the most dominant. Informants in this study consisted of primary and secondary sources, the primary sources were individuals or native Aneuk Jamee selected by random sampling. The secondary sources are informants who are not native to Aneuk Jamee but have insight and knowledge regarding the history and customs of Aneuk Jamee. The results of the study concluded that the Aneuk Jamee community has similarities with the system in the Minangkabau community in West Sumatra, namely adopting a hereditary system from the mother's side or commonly referred to as Matrilineal. Even though there has been Islamization in Aceh where the father is a descendant of the lineage, the matrilineal system is still evident in kinship (household) matters. All matters that will be carried out in a household must be discussed in advance with the ninik mamak (mother's brother).
\end{abstract}

Keywords: Culture, Family System, Aneuk Jamee.

\begin{abstract}
Abstrak
Suku Aneuk Jamee merupakan alkulturasi dari suku Aceh dan Minangkabau, keduanya seperti sudah menyatu dalam satu individu sehingga menghasilkan sebuah etnis yang baru. Etnis ini yang kemudian berkembang di Aceh Selatan serta mempengaruhi berbagai aspek budaya serta sistem kekeluargaan di dalamnya. Penelitian ini tergolong dalam penelitian lapangan dengan pendekatan kualitatif.
\end{abstract}


Adapun metodologi yang digunakan adalah fenomenologi yang didukung oleh literasi historis di wilayah Aceh Selatan dimana etnis aneuk jamee paling dominan. Informan dalam penelitian ini terdiri dari sumber primer dan skuner, sumber primernya adalah individu atau warga asli aneuk jamee yang dipilih secara random sampling. Adapun sumber sekundernya adalah informan yang bukan etnis asli aneuk jamee namun memiki wawasan dan pengetahuan terkait sejarah dan adat istiadat aneuk jamee. Hasil penelitian menyimpulkan bahwa masyarakat Aneuk Jamee memiliki kemiripan dengan sistem pada masyarakat Minangkabau di Sumatera Barat yaitu menganut sistem keturunan dari pihak ibu atau biasa disebut dengan Matrilineal. Meskipun sudah terjadi islamisasi di Aceh dimana ayah menjadi sanad garis keturunan, sistem matrilinieal masih kentara pada urusan kekeluargaan (rumah tangga). Segala sesuatu urusan yang akan diksanakan disebuah rumah tangga haruslah dibicarakan terlebih dahulu dengan ninik mamak (Abang dari pihak ibu).

Kata kunci : Budaya, Sistem Kekeluargaan, Aneuk Jamee.

\section{Pendahuluan}

Masyarakat Aceh Selatan adalah masyarakat yang multietnis, hal ini disebabkan oleh karena ketika masa Kesultanan Aceh pernah membuka Pelabuhan Haji di wilayah Aceh Selatan. ${ }^{1}$ Fungsi pelabuhan tersebut adalah untuk pemberangkatan Jamaa'ah Haji yang berasal dari berbagai wilayah di pantai Barat Sumatra sehingga banyak orang-orang yang berdatangan dari luar daerah. Mereka yang datang tersebut tidak jarang mereka menikah dengan penduduk sekitar dan menetap diwilayah tersebut.

Masyarakat Aneuk Jamee di Kabupaten Aceh Selatan tinggal di pesisir barat Aceh memiliki perbedaan dengan dengan orang-orang Aceh lainnya. Meskipun perbedaan fisik tidak begitu terlihat, namun perbedaan dapat dilihat dengan jelas dalam segi budaya, bahasa dan sejarahnya. Tokoh masyarakat jelas mengatakan bahwa suku Aneuk Jamee dan Aceh merupakan dua suku yang berbeda. Jika dilihat dari budayanya, suku Aneuk Jamee adalah percampuran dua buah suku yaitu suku Aceh dan suku Minangkabau.

Jika dilihat dari perspektif sejarahnya, yang disebut Aneuk Jamee merupakan mereka yang pernah tinggal di wilayah Minangkabau pada masa Kesultanan Aceh. Kemudian ketika Kesultanan Aceh mengalami kemunduran mereka kembali ke Aceh, karena sudah lama tinggal di Minangkabau mereka kembali dengan membawa kebiasan-kebiasaan disana. Perkembangan suku Anuek Jamee tidak hanya sampai disitu saja, Keberadaannya semakin ramai terjadi ketika perang padri berkecamuk di Minangkabau, kemudian mereka yang merasa terancam hidupnya melakukan migrasi ke wilayah pesisir barat Aceh.

\footnotetext{
${ }^{1}$ Essi Hermaliza, "Sistem Kekerabatan Suku Bangsa Kluet di Aceh Selatan The Kinship System Of Kluet Etnics In South Aceh,” n.d., 10.
} 
Alur sejarah dan budaya aneuk jamee mempengaruhi konsep keluarga di dalamnya. Konsep keluarga memiliki kaitan yang sangat erat dengan kekerabatan, seperti dua sisi mata uang yang tidak bisa saling terpisahkan. Kelompok keluarga yang meluas melalui garis keturunan ibu, telah mencapai tingkat kedua dalam proses perkembangan kebudayaan manusia. Garis keturunan dari pihak ibu di sebut matriarkhat oleh Wilken. ${ }^{2}$ Sementara bagi para pria yang merasa tidak puas dengan keadaan, kemudian mengambil isteri dari kelompok-kelompok lain yang kemudian mereka membawanya ke dalam kelompok mereka sendiri. Keturunan yang lahir dari hubungan itu kemudian tetap tinggal dalam kelompok pria, sehingga lambat laun timbul kelompok keluarga dengan ayah sebagai kepala dan disebut sebagai patriarkhat.

Sejarah dan budaya layaknya administrasi dalam suatu etnis, ia memainkan peran penting dalam terbentuknya sistem kekerabatan dan sistem kekeluargaan suatu wilayah. ${ }^{3}$ Begitu juga etnis aneuk jamee yang memiliki garis historis menarik. Meskipun aneuk jamee termasuk dalam wilayah Aceh, namun ia menjadi salah satu etnis yang unik dan berbeda dari etnis Aceh pada umumnya. Mereka memiliki bahasa sendiri serta kearifan lokal yang berbeda. Etnis aneuk jamee menjadi pelengkap dari kekhazanahan Aceh yang terdiri dari berbagai suku dan bahasa.

\section{Sejarah Aneuk Jamee}

Ekspansi Aceh ke pesisir Timur dan Barat kemudian dimulai pada masa Sultan Alaudin Riatsyah al Qahhar (1539-1571) yang kemudian mencapai puncak kejayaannya pada masa Sultan Iskandar Muda (1607-1636). Tidak butuh waktu lama untuk Aceh menakhlukkan wilayah tersebut, hal itu dikarenakan wilayah yang terbentang sepanjang Samudra Indonesia tersebut terbagi menjadi kerjaankerajaan dan nagari-nagari kecil. Dengan demikian, cukup dengan pasukan yang kecil dan waktu yang relative singkat wilayah Minangkabau dapat dikuasai oleh Kesultanan Aceh. ${ }^{4}$ Tidak hanya urusan politik dan ekonomi, kekuasaan Kesultanan Aceh Darussalam di Minangkabau juga turut serta menyebarkan agama Islam. Putra dari Sultan Alauddin Riayatsyah al Qahar yang ditunjuk untuk menjadi panglima syahbandar di Pariaman kemudian membuka sebuah pesantren di Ulakan, yang kemudian lebih dekenal dengan sebutan Syeh Burhanuddin I.

Pengislaman masyarakat Minangkabau secara besar-besaran baru terjadi

\footnotetext{
2 Misnal Munir, "SISTEM KEKERABATAN DALAM KEBUDAYAAN MINANGKABAU: PERSPEKTIF ALIRAN FILSAFAT STRUKTURALISME JEAN CLAUDE LEVI-STRAUSS," Jurnal Filsafat 25, no. 1 (August 14, 2016): 1, https://doi.org/10.22146/jf.12612.

3 M. Anzaikhan, "Hakikat Administrasi Pemerintahan Islam," Al-Ijtima i: International Journal of Government and Social Science 5, no. 1 (October 30, 2019): 56-80, https://doi.org/10.22373/jai.v5i1.465.

4 Dwi Rini Sovia Firdaus et al., "Portrait of The Minangkabau Culture According to Hofstede's Six Cultural Dimensions," Sodality: Jurnal Sosiologi Pedesaan 6, no. 2 (September 13, 2018), https://doi.org/10.22500/sodality.v6i2.23229.
} 
setelah dominasi politik dan ekonomi jatuh ketangan Kesultanan Aceh. Meskipun di daerah rantau Minangkabau masyarakatnya sudah memeluk islam sejak abada ke-6-7 Masehi bahkan di abad ke 8 Masehi sudah ada rajanya yang memeluk agama islam. Kekayaan yang cukup melimpah di wilayah tersebut membuat Aceh cukup lama mempertahankan kedudukannya, kurang lebih hampir satu abad Aceh menjadi pembeli tunggal hasil-hasil bumi dan menjadi penjual tunggal kebutuhan di daerah Pesisir. ${ }^{5}$ Hasil alam yang dibeli oleh Aceh antara lain emas, lada, kamfer, benzoin (kemenyan), cengkeh buah dan kulit pala, kulit manis dan hasil lainnya. Sementara barang yang dijual dari mereka adalah tekstil dan barang-barang mewah.

Melimpahnya hasil alam yaitu lada dan emas di tanah Minangkabau yang membuat Aceh tertarik datang di abad ke-16 dan kemudian menguasainya. Dengan adanya hubungan dagang dan politik tersebut juga tersebarnya agama islam di alam Minangkabau. Hingga akhirnya pada masa kepemimpinan Ratu Tadjul Alam Sjafiat-ud Din (1641-1676) kekuasaan aceh di alam Minangkabau mengalami penurunan. ${ }^{6}$ Penurunan kekuasaan tersebut dikarenakan rasa tidak puas dari orang Minangkabau dimana Kesultanan Aceh membeli hasil buminya dengan harga rendah sementara menjual barang-barang kebutuhan lainnya dengan harga yang sangat tinggi.

Kemudian kesempatan ini dimanfaatkan oleh Belanda dan Inggris untuk mengambil alih kekuasaan dengan cara mengadu domba. Strategi yang dilakukan Belanda dan Inggris berhasil, hal ini dikarenakan letak geografisnya yang jauh dari pusat pemerintahan sehingga monopolinya tidak bisa dipertahankan. Selain itu adanya keinginan dari orang-orang pesisir yang ingin melepaskan diri dari dominasi politik dan ekonomi Kesultanan Aceh telah lama bergejolak. Hal itu dikarenakan tekanan dari berbagai pajak dan perlakuan-perlakuan tidak wajar yang dilakuakn oleh pihak penguasa Aceh. Selain itu pamor Kesultanan Aceh juga sudah mulai menurun sejak dilakukannya perjanjian abadi antara Kesultanan Aceh dengan Kolonial Belanda.7 Selanjutnya penguasa di Tiku juga ingin melepaskan diri dari kekuasaan Aceh dan mereka meminta perlindungan kepada Belanda. Kemudian ketika Groenewegen kembali ke Padang, mereka melakukan perundingan dengan penghulu-penghulu di Padang, mereka siap untk mengusir Panglima dan orang-orang Aceh dari Bandar mereka dengan syarat Kompeni mau memberikan bantuannya.

\footnotetext{
${ }^{5}$ Sovia Firdaus et al.

${ }^{6}$ Iva Ariani, "NILAI FILOSOFIS BUDAYA MATRILINEAL DI MINANGKABAU (RELEVANSINYA BAGI PENGEMBANGAN HAK-HAK PEREMPUAN DI INDONESIA)," Jurnal Filsafat 25, no. 1 (August 14, 2016): 32, https://doi.org/10.22146/jf.12613.

${ }^{7}$ Anwar Anwar, "Strategi Kolonial Belanda Dalam Menaklukkan Kerajaan Aceh Darussalam," Jurnal Adabiya 19, no. 1 (July 17, 2020): 13, https://doi.org/10.22373/adabiya.v19i1.7482.
} 
Dilakukan perundingan pada bulan April 1663 di Casteel van Batavia antara utusan-utusan dari Raja nan Empat dengan Joan Maetsucker. Utusan Raja nan Empat yaitu terdiri dari Raja Panjang (anak Raja Carbou dan Raja Lelo), Raja Indrapura (Sultan Mansyursyah merupakan putra dari Sultan Muhammadsyah), dari Tiku Bandar Chalifah (Orang Kecil) dan dari Padang (Orang kaya kecil). Dari sinilah terjadinya kesepakatan yang kemudian dikenal dengan perjanjian Painan. ${ }^{8}$

Perjanjian Painan tersebut berisikan tentang pemerintah colonial Belanda diberikan hak monopoli untuk berdagang di daerah Indrapura dan tempat-tempat lain yang menjadi wilayah taklukan pemerintahnya, tanpa membayar pajak kecuali persembahan-persembahan kepada penguasa setempat seperti yang biasa dilakukan pada masa sebelumya. Indrapura dan wilayah-wilayah taklukkannya akan mengusir panglima-panglima dan pejabat-pejabat Aceh lainnya dari wilayah mereka dan Kompeni akan melindungi mereka dari musuh yang menyerang dari arah laut.

Setelah perjanjian Painan tersebut, terjadilah perang saudara yang mengakibatkan kekacauan terjadi dimana-mana.hal ini disebabkan karena Gubernur militer Kesultanan Aceh yang di Pariaman tidak ikut menandatangani Perjanjian Painan tersebut. Tindakan-tindakan Belanda tersebut memicu kemarahan kaum Penghulu Adat yang kemudian menumbuhkan perlawanan untuk mengusir Belanda dari daerah Minangkabau.

Namun untuk melawan Belanda sendirian dirasa tidak akan berhasil, sehingga perlu adanya kerjasama dengan kaum Padri. Permintaan kaum Penghulu Adat untuk bersatu dalam melawan pemerintah colonial Belanda disambut baik oleh kaum Padri, gerakan tersebut langsung dipimpin oleh Imam Bonjol. Namun pertempuran panjang yang tidak kunjung usai membuat pasukan Imam Bonjol kewalahan dan benteng Bonjol berhasil dihancurkan. Karena kondisi tersebut Imam Bonjol menyerukan kepada pasukannya yang terserak di mana-mana untuk kembali ke kampung halamannya masing-masing dan memulai hidup baru sebagai rakyat biasa. Sedangkan bagi mereka yang tidak memiliki lagi semangat berjuang dibiarkan untuk menyerah kepada pemerintah kolonial Belanda. Dalam pertempuran ini berakhir dengan penangkapan Imam Bonjol dan pasukannya. ${ }^{9}$

Selain karena wilayah Minangkabau merupakan bagian dari Kesultanan Aceh, kedatangan orang-orang Minangkabau ke Aceh bagian Barat juga dipicu oleh pecahnya Perang Padri pada awal abad ke-19 di wilayahnya. Perang Padri ini

\footnotetext{
${ }^{8}$ M. Nazaruddin, "Dimensi pembentuk kesadaran identitas keacehan dan citra diri Aceh," Masyarakat, Kebudayaan dan Politik 27, no. 1 (January 1, 2014): 44, https://doi.org/10.20473/mkp.V27I12014.44-54.

${ }^{9}$ Humar Sidik, "CHRISTIAAN SNOUCK HURGRONJE DALAM DINAMIKA ISLAM DI ACEH PADA MASA KOLONIAL BELANDA," Jurnal Artefak 7, no. 1 (May 1, 2020): 31, https://doi.org/10.25157/ja.v7i1.3282.
} 
bermula masuknya Paham Wahabi ke Minangkabau. Masuknya paham Wahabi ini berawal dari pulangnya tiga orang Minangkabau dari Mekkah yaitu Haji Sumanik dari luhak Tanah datar, Haji Piobang dari luhak Lima Puluh Kota dan Haji Miskin dari luhak Agam. ${ }^{10}$ Pada tahun 1803 mereka pulang ke Luhak masing-masing, dengan semangat faham Wahabi yang berasal dari Tanah Arab dan melaksanakan penertiban terhadap praktek-praktek yang melanggar hukum agama seperti berjudi, menyabung ayam, mabuk-mabukan serta kebathilan lain yang telah merajalela. Maka dengan demikian pecahlah Perang Padri pada awal abad ke-19, pecahnya Perang Padri bersamaan dengan terjadinya persaingan ekonomi antara dua kekuatan kolonial di Asia Tenggara.

Peristiwa perang Padri yang terjadi di Minangkabau terbagi dalam tiga periode. Periode yang pertama terjadi tahun 1809-1821, perang ini melibatkan kaum Padri yang melawan kaum Adat. Gerakan ini dilakukan untuk oleh kaum Padri untuk membersihkan golongan Penghulu Adat yang dianggap menyimpang dan bertentangan dengan syari'at Islam. Sehingga periode ini terjadi pertempuran yang melibatkan kaum Padri melawan kaum Penghulu Adat.

Periode kedua terjadi pada tahun 1821-1832, pertempuran ini terjadi atara kaum Padri dengan Belanda. Belanda mendapatkan dukungan penuh dari kaum Penghulu Adat, dukungan tersebut diberikan karena kaum Penghulu Adat mengalami kekalahan dalam pertempuran pertama yang terjadi pada tahum 18091821. Pertempuran pada periode kedua ini dimenangkan Belanda yang dibantu oleh kaum Penghulu Adat. Kekalahan kaum Padri karena daerah-daerah pelabuhan jatuh ke tangan Belanda sehingga pasukan Padri yang berpusat di benteng Bonjol mendapat kesulitan, terutama dalam memeproleh suplai bahan makanan dan persenjataan. ${ }^{11}$

Sementara periode ketiga terjadi pada tahun 1832-1837, diperiode ini kaum Padri dan kaum Penghulu Adat bersatu untuk melawan Belanda. Pada periode sebelumnya kaum Penghulu Adat berpihak kepada Belanda, namum pada periode kali ini kaum Penghulu Adat berpihak kepada kaum Padri. Hal ini disebabkan oleh sikap sombong dan moral bejat yang dipertontonkan oleh pasukan Belanda diantaranya menjadikan Masjid sebagai asrama militer dan tempat minum-minuman keras, mengusir rakyat kecil dari rumah mereka, pembantaian masal, pemerkosaan terhadap wanita dan lainnya. ${ }^{12}$

\footnotetext{
10 Anwar, "Strategi Kolonial Belanda Dalam Menaklukkan Kerajaan Aceh Darussalam."

11 Safwan Rozi, "NEGOSIASI ISLAM KULTUR DALAM GERAKAN PADERI RAO DI SUMATERA TENGAH (1820-1833)," KALAM 6, no. 1 (February 24, 2017): 85, https://doi.org/10.24042/klm.v6i1.396.

12 Rozi.
} 


\section{Sebaran Etnis Aneuk Jamee}

Masyarakat Aneuk Jamee di Kabupaten Aceh Selatan tinggal di pesisir barat Aceh memiliki perbedaan dengan dengan orang-orang Aceh lainnya. Meskipun perbedaan fisik tidak begitu terlihat, namun perbedaan dapat dilihat dengan jelas dalam segi budaya, bahasa dan sejarahnya. Tokoh masyarakat jelas mengatakan bahwa suku Aneuk Jamee dan Aceh merupakan dua suku yang berbeda. Jika dilihat dari budayanya, suku Aneuk Jamee adalah percampuran dua buah suku yaitu suku Aceh dan suku Minangkabau.

Jika dilihat dari perspektif sejarahnya, yang disebut Aneuk Jamee merupakan mereka yang pernah tinggal di wilayah Minangkabau pada masa Kesultanan Aceh. Kemudian ketika Kesultanan Aceh mengalami kemunduran mereka kembali ke Aceh, karena sudah lama tinggal di Minangkabau mereka kembali dengan membawa kebiasan-kebiasaan disana. Perkembangan suku Anuek Jamee tidak hanya sampai disitu saja, Keberadaannya semakin ramai terjadi ketika perang padri berkecamuk di Minangkabau, kemudian mereka yang merasa terancam hidupnya melakukan migrasi ke wilayah pesisir barat Aceh.

Ketika berbicara Minangkabau tentunya tidak terlepas dari budaya merantaunya. Pada dasarnya merantau merupakan kebiasaan yang telah dilakukan sejak lama oleh masyarakat di Indonesia. Berbagai suku dan bangsa melakukan merantau yang dimaknai dengan pergi ke Negara lain meninggalkan kampong halaman, baik berlayar menggunakan sungai atau dengan cara lainnya. Merantau dijadikan sebagai ajang untuk belajar mengenai kehidupan, kematangan dalam menjalin pahit dan manisnya kehidupan. ${ }^{13}$

Sehingga keberadaan orang-orang Minangkabau di Aceh tidak hanya sekedar karena peperangan saja, melainkan jauh sebelum terjadinya perang padri sudah banyak orang-orang Minangkabau di Aceh. Perjalanan orang Minangkabau ke Aceh tercatat kurang lebih pada abad ke-17 yang dilakukan oleh si Nahkoda Saleh. Nahkoda Saleh berlayar ke Singkil untuk melakukan perdagangan, sebab pada abad ke-17 tersebut Singkil menjadi salah satu Bandar penting di masa Kejayaan Kesultanan Aceh. Selain ke singkil Nahkoda Saleh juga berlayar hingga ke Tapaktuan dan Meulaboh. ${ }^{14}$

Dari jejak sejarah dan stereotipe yang berkembang dalam masyarakat Aneuk Jameee nenek moyang mereka memanglah datang dari Minangkabau yang kemudia menetap di Pantai Barat Aceh. Mereka yang datang turut membawa serta budayanya, sehingga seiring berjalannya waktu budaya Minangkabau tersebut berakulturasi dengan budaya setempat yaitu budaya Aceh. Kemudian

\footnotetext{
${ }^{13}$ Suci Marta, "KONSTRUKSI MAKNA BUDAYA MERANTAU DI KALANGAN MAHASISWA PERANTAU," Jurnal Kajian Komunikasi 2, no. 1 (2014): 17.

${ }^{14}$ Rayvaldo Anggriawan Asmon and Zakwan Adri, "MOTIVASI MERANTAU PADA REMAJA AKHIR MINANGKABAU," 2021, 7.
} 
mereka dilabeli sebagai Aneuk Jamee wadalam bahasa Aceh artinya adalah Anak tamu. Seringi perkembangan zaman, kelompok masyarakat yang disebut sebagai Aneuk Jamee ini menjadi sebuah suku. Suku Aneuk Jamee memiliki budaya sendiri yang berbeda dengan suku Aceh. Hubungan yang tidak kalah penting adalah hubungan antara suku Aneuk Jamee dengan suku Minangkabau. Hubungan yang sangat erat terlihat karena adanya persamaan dalam bahasa, adat istiadat yang memiliki kemiripan.

\section{Budaya Aneuk Jamee}

Adat memiliki kegunaan untuk mengatur segala bentuk kehidupan masyarakat, adat ini telah digunakan sebelum adanya undang-undang yang mengatur roda pemerintahan dalam sebuah Negara seperti sekarang ini. Adat digunakan sebagai landasan kelompok masyarakat untuk mengatur seriap anggota masyarakatnya agar hidup rukun dan damai serta mematuhi segala aturan hidup berkelompok. ${ }^{92}$ Seperti hukum adat perkawinan, bukan hanya masalah pribadi-pribadi yang melakukan perkawinan tersebut, tetapi juga termasuk masalah keluarga besar yang bersangkutan. Baik dari mencarikan pasangan, pertunangan dan sampai pada tahap akibat-akibat yang ditimbulkan dari perkawinan tersebut. Dengan demikian dapat disimpulkan jika perkawinan dalam hukum adat tidak hanya menyangkut masalah pengantin laki-laki dan perempuan tetapi juga masalah keluarga dari kedua pihak dan sistem masyarakatnya yang berlaku. ${ }^{15}$

Tak terkecuali bagi suku Aneuk Jamee, adat sangat dijunjung tinggi dalam kelompok masyarakat ini. Setiap masyarakat tunduk dan mematuhi adat yang telah ditetapkan terlebih mereka merupakan suku yang berakulturasi dari dua buah budaya yaitu Minangkabau dan Aceh. seperti yang tertuang dalam pepatah Aneuk Jamee "Adat Basimpue Sentak, Syariat Basimpu Mati" simpul sentak berarti seperti tali yang diikat simpulnya dapat terbuka dengan mudah dengan menarik ujung tali yang bersimpul tersebut. Kemudian syaiat beasimpue mati berarti syariat tidak boleh dirubah atau tidak boleh ditambah ataoun dikurangi, sehingga dikatakan bersimpul mati yang maksudnya tidak boleh dibuka lagi. Kemudian artinya adat boleh ditambah dan dikurangi sesuai dengan situasi dan kondisi juga sesuai dengan kebutuhan masyarakat disuatu tempat.16 Pepatah tersebut sama dengan adat Aceh yang tertuang dalam hadih maja, bunyinya ialah sebagai berikut:

\section{Adat meukong reubong}

\footnotetext{
15 Helzi Ramanta and Samsuri Samsuri, "The Values of Local Wisdom of Minangkabau Culture in a Baralek Gadang Traditional Wedding," Humaniora 11, no. 3 (November 30, 2020): 193-201, https://doi.org/10.21512/humaniora.v11i3.6625.

${ }^{16}$ Hermaliza, "SISTEM KEKERABATAN SUKU BANGSA KLUET DI ACEH SELATAN THE KINSHIP SYSTEM OF KLUET ETNICS IN SOUTH ACEH."
} 
Hukom meukong purieh

Adat barang gapat jiet takhong

Hukom barang gapat han jiet takieh ${ }^{17}$

Arti dari hadih maja tersebut ialah Adat meukong reubong artinya adat memotong rebung (tunas bamboo yang biasa dimasak menjadi gulai) boleh dikupas dan dipotong kecil-kecil, begitulah diibaratkan dengan adat. Hukom meukoh purieh, memiliki makna seperti orang yang membuat tangga dari sebatang bambu, jika bamboo tersebut ingin dijadikan tangga maka maka rantingnya tidak boleh dipotong habis. Karena jika rantingnya dopotong habis maka tidak ada lagi cabang yang digunakan untuk berpijak ketika menaiki tangga bamboo tersebut. Adat barang gapat jiet takhong berarti adat dimana saja boleh didobrak dalam arti adat boleh dikurangi ataupun ditambah sesuai dengan aturan dan keadaan ataupun situasinya. ${ }^{18}$ Hukom barang gapat hanjiet takieh artinya ialah hukum syariat tidak boleh diusik, karena hukum syariat merupakan hukum agama yang berpedoman pada Al-qur'an dan Hadist.

Masyarakat Aneuk Jamee merupakan kelompok masyarakat yang masih kental akan adat dan budayanya. Adat menjadi gambaran jadi diri dari suatu kelompok masyarakat yang harus tetap dipertahankan demi terjaganya sebuah tatanan kehidupan yang arif dan bijaksana. Aturan-aturan yang berlaku dalam sebuah adat tidaklah tertulis namun tetap di taati dan dilaksanakan oleh setiap anggota kelompok masyarakat.

\section{Kain Kasab dalam Aktivitas Kekeluargaan}

Kasab adalah kerajinan sulaman benang emas yang diaplikasikan ke permukaan kain beludru dengan teknik padded counching sehingga menghasilkan kesan tiga dimensi. Kasab selalu digunakan dalam setiap upacara adat daur hidup seperti, upacara pernikahan, upacara adat sunat rasul, upacara adat kematian dan upacara adat Peusijuk. ${ }^{19}$ Penggunaan benang emas dalam dekorasi upacara adat merupakan lambang derajat sosial seseorang dalam melaksanakan upacara adat.

Benang emas dipilih untuk menyulam kasab tidak hanya karena ingin memberikan nilai estetis saja, tetapi bagi masyarakat Aneuk Jamee penggunaan bahan dapat menjadi pelengkap makna yang disampaikan melalui simbol-simbol. Kasab tidak hanya sebagai dekorasi dalam pelaksanaan upacara adat, lebih dari itu

${ }^{17}$ Mohammad Harun, "REVITALISASI NILAI ETOS KERJA DALAM HADIH MAJA SEBAGAI BAHAN AJAR PENDIDIKAN KARAKTER," Journal of Educational Science and Technology (EST) 1, no. 3 (December 14, 2015), https://doi.org/10.26858/est.v1i3.1824.

${ }^{18}$ Erwina Gusti and Siti Aisah Ginting, "THE FADING OF HADIH MAJA IN THE VERNACULAR LANGUAGE AMONG ACEHNESE TEENAGERS IN BANDA ACEH," 2016, 5.

${ }^{19}$ Zulfikar Zulfikar, Adi Isworo Josef, and Ratna Endah Santoso, "PENERAPAN TEKNIK KASAB ACEH PADA PRODUK SEPATU WANITA DEWASA," CORAK 8, no. 2 (August 3, 2019): 113-22, https://doi.org/10.24821/corak.v8i2.2793. 
kasab memiliki peran dalam penyampaian pesan filosofis melalui simbol-simbil yang digunakan melalui letaknya. Nuansa filosofis dianggap penting karena ia adalah landasan dari berkembanganya keyakinan dan kebiasaan suatu masyarakat. ${ }^{20}$

Peletakan simbol sangat berpengaruh dalam pesan yang disampaikan karena kasab beralih fungsi sesuai dengan peletakkan simbolnya. Sehingga kasab tidak boleh dipasang sembarangan, pemasangan kasab harus dilakukan oleh orang-orang tertentu. Beberapa makna dalam penggunaan kasab dalam setiap upacara-upacara adat pada masyarakat Aneuk Jamee diantaranya; Pertama, upacara adat perkawinan. Dalam adat perkawinan, selain menjadi dekorasi ruangan juga menympaikan pesan tentang pelaksanaan adat.21 Beberapa komponen yang termasuk dalam dekorasi kasab untuk adat pernikahan adalah meracu (kasab segitiga), tapak, kipeh (kipas), banta gadang (bantal besar), dalansi (bentangan kain), banta basusun (bental bersusun), tabia (tabir), lidah-lidah, tilam pundak (duduk).

Kedua, upacara adat kematian. Kasab yang digunakan dalam pelaksanaan upacara adat kematian digantung tepat di atas kepala tempat tidur salah satu ruangan. Hal tersebut menyampaikan pesan kepada masyarakat bahwa di rumah tersebut sedang berduka atas kepergian sanak saudara. Komponen kasab yang digunakan dalam upacara adat kematian adalah tabir dan meracu. ${ }^{22}$ Tetapi jika yang meninggal adalah golongan bangsawan atau raja maka kasab yang digunakan adalah tabir sebagai penutup dinding. Kemudian bagian tengah dinding tepat di atas kepala tempat tidur digantungkan meracu tunggal dan tapak meracu tunggal. Meracu tunggal dan tapak meracu tunggal tersebut menyimbolkan Tuhan Yang Maha Esa.

Ketiga, upacara adat sunat rasul. Kasab dalam upacara adat sunat rasul tidak berbeda jauh dengan kasab pada upacara adat pernikahan. Yakni terdiri dari meracu (kasab segitiga), tapak, kipeh (kipas), banta gadang (bantal besar), dalansi (bentangan kain), banta basusun (bantal bersusun), tabia (tabir), lidah-lidah dan tilam pandak (duduk). Keempat, Peusijuek berasal dari bahasa Aceh yaitu Sijuek kemudian ditambah Peu diawalalan. Sijuek artinya ialah dingin sementara Peu yang membuat susuatu menjad sehingga Peusijuek artinya menjadikan sesuatu

\footnotetext{
${ }^{20}$ M. Anzaikhan, "Urgensi Filsafat dalam Ilmu Falak dan Relevansinya bagi Kehidupan Beragama Masyarakat," Substantia: Jurnal Ilmu-Ilmu Ushuluddin 22, no. 2 (October 30, 2020): 107, https://doi.org/10.22373/substantia.v22i2.7664.

${ }^{21}$ Mursyidin Mursyidin et al., "Understanding Acehnese Proverbs and Their Relation to the Community Work Ethics," n.d., 6.

22 T Junaidi and Mufti Riyani, "RAGAM HIAS ACEH: CORAK IDENTITAS DAN PEMAKNAANNYA

DALAM MASYARAKAT NELAYAN DAN PELADANG," 2017, 20.
} 
agar menjadi dingin.23 Masyarakat Aneuk Jamee melakukan Peusijuek untuk berbagai macam acara adat seperti, perkawinan, sunat rasul, orang-orang yang ingin melakukan perjalanan ke Tanah Suci dan lainnya. Dalam kegiatan adat ini, kasab juga digunakan sebagai hiasan untuk menambah keindahan.

Kelima, acara formal. Kasab juga biasa digunakan dalam acara-acar formal yang diselanggarakan oleh pemerintah Kabupaten Aceh Selatan. Penggunan Kasab ini bertujuan untuk tetap melestarikan budaya Aneuk Jamee. Kasab juga menjadi identitas dan ciri khas dari Kabupaten Aceh Selatan. Secara filosofi, kasab merupakan perwakilan dari status sosial seseorang, sebab jika jika bangsawan yang menggelar acara upacara adat maka komponenkomponen yang digunakan akan lebih lengkap serta lebih menggah.

Termasuk dalam pemilihan warna juga akan berbeda, biasanya jika golongan bangsawan akan menggunakan warna kuning, sedangkan untuk masyarakat biasa hiasannya akan lebih sederhana dan warna yang digunakan adalah warna merah saja. Kasab menjadi salah satu benda adat yang memiliki nilai seni. Karena pada hakikatnya kasab memiliki peran menyampaikan pesan, sombol, nasihat maupun isyarat dalam sebuah pelaksanaan upacara adat melalui motifmotif, bentu dan komponenkomponen dari kasab itu sendiri. ${ }^{24}$

\section{Sistem Kekerabatan Aneuk Jamee}

Kekerabatan terbangun karena adanya berbagai sebab perkawinan di luar kelompok (eksogami) berubah menjadi perkawinan dalam batas-batas kelompok (endogami). Endogami menyebabkan anak-anak selanjutnya dapat berhubungan secara leluasa dengan anggota kerabat ayah maupun ibu. Sehingga, patriarkhat semakin lama semakin hilang dan berubah menjadi susunan kerabat parental. 25

Kekerabatan berkembang dari yang jumlahnya kecil sampai kepada jumlah yang besar. Diperkirakan kekerabatan bermula dari pola matrilineal yang lama kelamaan menjadi patrilineal. Namun tidak menutup kemungkinan berawal dari pola patrilineal yang lama kelamaan menjadi matrilineal. Hal tersebut bisa terjadi karena adanya pertemuan dua keluarga atau lebih yang sama-sama patrilineal yang mengadakan perkawinan silang dan akhirnya tetap membentuk pola

\footnotetext{
${ }^{23}$ Hermaliza, "SISTEM KEKERABATAN SUKU BANGSA KLUET DI ACEH SELATAN THE KINSHIP SYSTEM OF KLUET ETNICS IN SOUTH ACEH."

${ }^{24}$ Widyanan Wulandari Z, Ismawan, Lindawati, "Peran Kasab dalam Upacara Adat MAsyarakat Suku Aneuk Jamee Kecamatan Tapak Tuan”, dalam Jurnal Ilmiah Mahasiswa Program Studi Pendidikan Seni Drama, Tari dan Musik Fakultas Keguruan dan Ilmu Pendidikan Unsiyah. Volume I, Nomor 4, (November 2016), hlm. 313-324.

${ }^{25}$ Muhammad Nasir Khalidah, "Penyelesaian Pembagian Warisan Di Kecamatan Simpang Ulim Dalam Perspektif Hukum Islam dan Hukum Adat," Al-Qadha : Jurnal Hukum Islam dan PerundangUndangan 8, no. 1 (July 12, 2021): 33-49, https://doi.org/10.32505/qadha.v8i1.2997.
} 
patrilineal.26 Menurut Suparlan (1986) sistem kekerabatan merupakan serangkaian aturan-aturan yang mengatur penggolongan orang-orang yang sekerabat, melibatkan adanya berbagai tingkat hak dan kewajiban diantara orangorang yang sekerabat, hal tersebutlah yang membedakannya dengan hubunganhubungan mereka dengan orang-orang tidak tergolong sebagai kerabat.

Sementara menurut Keesing (2008) kekerabatan kadang kala menunjukkan pada hubungan darah. Jadi kekerabatan diartikan mereka yang bertalian berdasarkan ikan dengan darah, sedangkan kerabat perkawinan merupakan ikatan karena perkawinan bukan karena hubungan darah. Kekerabatan yang dimaksud ialah keturunan antara orang tua dan anaklah yang merupakan ikatan pokok kekerabatan. ${ }^{27}$

Menurut Robin sistem kekerabatan menentukan posisi seseorang dalam masyarakat yaitu posisi laki-laki dan perempuan. Pada kekerabatan yang menganut siste patrilineal posisi laki-laki lebih penting daripada posisi perempuan dan sebaliknya pada sistem kekerabatan yang menganut sistem matrilineal posisi perempuanlah yang lebih penting. Selain sistem kekerabatan patrilineal dan matrilineal terdapat juga sistem kekerabatan non ulineal yaitu bilineal dan bilateral.28 Menurut Marzali (2000) masyarakat yang menganut sistem kekerabatan matrelinela memeliki ciri-ciri diantaranya ialah keturunan ditelusuri melalui garis wanita, anggota kelompok keturunan direkrut melalui garis wanita dan pewaris harta dan suksesi politik disalurkan melalui garis wanita.

Hal yang sama juga dikatakan oleh Thaher (2006) pada dasarnya dalam susunan masyarakat adat yang memeprtahankan garis keturuan ibu (matrilineal) yang berhak menjadi ahli waris adalah anak-anak perempuan sedangkan anak lakilaki bukan ahli waris. Menurut Wilken garis keturunan matrilineal merupakan garis keturunan yang tertua dibandingkan garis keturunan lainnya. ${ }^{29}$

Kekerabatan dapat dianggap sebagai semacam bahasa sebab aturan-aturan yang diikuti klan-klan primitif di bidang kekerabatan dan perkawinan memang merupakan suatu sistem. Sistem-sistem itu terdiri atas relasi-relasi dan oposisioposisi seperti suami-istri, bapak-anak, saudara laiki-laki-saudara perempuan. Sistem kekerabatan juga memiliki hubungan dengan sistem bahasa. Kekerabatan dan bahasa merupakan sistem komunikasi dan di dalamnya terdapat ketidak sadaran ada unsur-unsur dan aturan-aturan yang tidak disadari.

\footnotetext{
${ }^{26}$ Ariani, "NILAI FILOSOFIS BUDAYA MATRILINEAL DI MINANGKABAU (RELEVANSINYA BAGI PENGEMBANGAN HAK-HAK PEREMPUAN DI INDONESIA)."

${ }^{27}$ Ramanta and Samsuri, "The Values of Local Wisdom of Minangkabau Culture in a Baralek Gadang Traditional Wedding."

${ }^{28}$ Marta, "KONSTRUKSI MAKNA BUDAYA MERANTAU DI KALANGAN MAHASISWA PERANTAU."

${ }^{29}$ Yulita Fitriana, "SISTEM KEKERABATAN MATRILINEAL DALAM MITOS 'MALIN KUNDANG,'” Jurnal Ilmu Budaya 15, no. 1 (November 4, 2018): 48-67, https://doi.org/10.31849/jib.v15i1.2032.
} 


\section{Sistem Kekeluargaan Aneuk Jamee}

Keluarga adalah sebuah hubungan yang memiliki pertalian darah, baik dari pihak ayah maupun pihak ibu. Yang dapat disebut keluarga merupaka mereka yang masih satu nenek dan kakek, baik dari kakek nenek dari pihak ayah beserta kaka dan adiknya maupun kekek nenek dari pihak ibu dengan kakak dan adiknya. Selian itu, anak-anak dari saudara kandung ibu dan ayah atau biasa disebut dengan sepupu juga merupakan keluarga. Diatas itu ada terdapats sebutan Dosanak, mereka adalah buyut beserta adik kakak dan kakek nenek beradik kakak samapai kepada keturunannya. ${ }^{30}$ Sistem kekerabatan tersebut tidak berlaku dalam semua sistem kekerabatan kelompok masyarakat, seperti halnya dalam sistem kekerabatan dalam masyarakat

Aneuk Jamee di Aceh Selatan yang biasanya disebut Dosanak. Selanjutnya Dosanak sendiri terbagi lagi menjadi dua golongan yaitu, dosanak dakek (akrab) dan dosanak kampuang. Dosanak dakek adalah mereka yang memiliki hubungan darah dari buyut, kakek beradik dan sampai paling bawah. Sementara dosanak kampuang adalah orang sekampung yang memiliki hubungan akrab seperti tetangga, orang yang belajar mengaji bersama. Mereka yang memiliki hubungan dosanak kampuang biasa juga disebut dengan induak samang (saudara angkat).

Kaum merupakan satu kelompok masyarakat yang masih satu rumpun atau satu keturunan. Satu kaum biasanya terdiri dari empat kaum delapan pihak. Yang dimaksud dengan satu kamu ialah jika sepasang suami istri yang telah menikah maka saudara dari ayah dan ibu kedua belah pihak menjadi kaumnya. Sementara delapan pihak ialah semua besan dari keluaga ayah dan ibu kedua belah pihak. Jadi dapat disimpulkan bahwa kaum adalah orang yang memiliki hubungan serumpun sementara pihak bukan yang berasal dari satu rumpun atau tidak memiliki pertalian darah. ${ }^{31}$

Kerabat adalah hubungan antara satu keluarga dengan keluarga lain yang erat dan akrab karena hubungan persahabatan, saling menghargai. Kemudian terjadi hubungan yang harmonis sehingga terbina hubungan erat antara satu pihak dengan pihak lainnya. Tidak jarang hubungan kerabat yang terjada akan menjadi sagat erat bahkan terlihat seperti saudara dekat yang memiliki ikatan darah. Beberapa hal yang bisa mempererat hubungan kerabat misalanya hubungan daganag atau tolong menolong.

Ninik Mamak merupakan saudara laki-laki dari pihak ibu baik abang dari ibu maupun adiknya. Ninik mamak memiliki peranan yang sangat besar dalam

\footnotetext{
30 Muslim Pohan, "Fenomena dan Faktor Perkawinan Semarga," Al-Qadha : Jurnal Hukum Islam dan Perundang-Undangan 8, no. 1 (July 14, 2021): 67-84, https://doi.org/10.32505/qadha.v8i1.2088.

${ }^{31}$ Jon Paisal, "Peran Dakwah Dalam Keluarga Dan Relevansinya Bagi Pembentukan Karakter Anak," Al-Qadha : Jurnal Hukum Islam dan Perundang-Undangan 8, no. 1 (July 14, 2021): 50-66, https://doi.org/10.32505/qadha.v8i1.2726.
} 
sisitem adat Aneuk Jamee. Biasanya peranan mereka mencakup dalam seluruh bidang terlebih keponkananya seorang perempuan. Ninik mamak juga menjadi panutan bagi kemenakannya, mereka bertanggung jawab penuh. ${ }^{32}$

Segala sesuatu urusan yang akan diksanakan disebuah rumah tangga haruslah dibicarakan terlebih dahulu dengan ninik mamak. Sebelum adanya musyawarah dengan ninik mamak maka kabar berita mengenai acar tersebut tidaklah boleh terdengar kepada masyarakat. Jika aturan tersebut dilanggar maka keluarga akan mendapatkan sanksi adat sesuai dengan aturan yang berlaku di wilayah tersebut. Bisan merupakan hubungan yang dihasilkan dari pernikahan seorang anak dari keluarga satu dengan anak dikeluarga lainnya. Kemudian kedua orang tua dari dua belah pihak inilah yang disebut dengan bisan.

Masyarakat Aneuk Jamee memiliki kemiripan dengan sistem pada masyarakat Minangkabau di Sumatera Barat yaitu menganut sistem keturunan dari pihak ibu atau biasa disebut dengan Matrilineal. Jaringan sosial antar kerabat perempuan sengaja dibangun pada masyarakat Minangkabau karena jaringan tersebut memiliki makna strategis bagi mereka. ${ }^{33}$

Pertama dari aspek ekonomi kerabat perempuan merupakan salah satu asset dan modal sosial yang dapat diandalkan untuk menjaga subsistensi maupun pemenuhan kebutuhan. Kedua, secara sosio-kultural jaringan sosial tersebut juga memiliki makna yang signifikan. Relasi dengan kerabat tidak hanya menunjukkan kepada orang luar bahwa sebuah keluarga/kaum merupakan suatu kesatuan yang kompak. Melainkan jaringan sosial berfungsi sebagai sarana bagi individu untuk menunjukkan tanggung jawab moral, tanggung jawab sosial, komitmen kesetiaan terhadap kerabat bahwa apa yang diperoleh seseorang sesungguhnya tidak pernah terlepas dari bantuan kerabat dan keluarga. ${ }^{34}$

\section{Penutup}

Multi etnis di Aceh Selatan sangat dipengaruhi oleh sejarah Kesultanan Aceh khususnya ketika dibukanya pelabuhan haji. Secara kuantitatif pelabuhan haji di Aceh Selatan membuat penduduk bagian Barat Sumatera berdomisili dan menikah dengan penduduk setempat. Akibatnya terjadilah akulturasi antara budaya Aceh dan Sumatera Barat (Minangkabau) yang kemudian berasimilasi menjadi etnis baru yaitu Aneuk Jamee. Singkatnya, etnis Aneuk Jamee bisa dikatakan sebagai kaum minangnya orang Aceh.

\footnotetext{
32 Hermaliza, "SISTEM KEKERABATAN SUKU BANGSA KLUET DI ACEH SELATAN THE KINSHIP SYSTEM OF KLUET ETNICS IN SOUTH ACEH."

33 Fitriana, "SISTEM KEKERABATAN MATRILINEAL DALAM MITOS 'MALIN KUNDANG."”

${ }^{34}$ Fika Andriana Dessy Asnita Agustinar \&, "Istri Bergaji: Analisis Peran Wanita Bekerja Dalam Meningkatkan Ekonomi Keluarga," Al-Qadha : Jurnal Hukum Islam dan Perundang-Undangan 8, no. 1 (July 12, 2021): 13-32, https://doi.org/10.32505/qadha.v8i1.2800.
} 
Secara historis, ada juga yang mengatakan bahwa suku Aneuk Jamee adalah etnis Aceh yang tinggal di Sumatera Barat ketika Aceh pada masa kejayaannya. Selanjutnya, ketika Kesultanan Aceh melemah, etnis Aceh tersebut kembali (remigrasi) ke tanah kelahirannya di Aceh Selatan. Selanjutnya, kalangan remigran ini yang menghadirkan etnis Aneuk Jamee di Aceh Selatan. Corak budaya dan kearifan lokal Aneuk Jamee mempengaruhi sistem kekerabatan dan kekeluargaan dalam masyarakat. Kebiasaan tradisional seperti adat perkawinan, sunnatan rasul, dan jamuan lainnya tak terlepas dari peran kaum ibu dalam otoritas keluarga. Nilai-nilai autentik Aneuk Jamee juga terlihat pada model busana dan kain kasab yang menjadi identitas tersendiri.

Etnis Aneuk Jamee memiliki sistem kekeluargaan yang unik, garis kerabat tidak hanya ditentukan oleh hubungan darah, Aneuk Jamee gemar mengangkat saudara atas dasar hubungan sosial (tetangga) akrab yang bahasa sederhananya disebut sebagai saudara angkat. Meskipun Aneuk Jamee eksist di Aceh, nilai-nilai Minangkabau masih tersirat dalam berbagai praktek-praktek acara adat dan kekeluargaan. Sebagai contoh, ketika menyangkut resepsi adat Aneuk Jamee, pihak keluarga harus meminta izin oleh ninik mamak (abang tertua di pihak ibu). Sebelum mendapat izin atau diskusi dengan ninik mamak maka keluarga dilarang untuk membahasnya dengan pihak lain, apalagi sampai diketahui masyarakat luas. Bahkan, jika pelanggaran itu terjadi, ada sanksi adat yang diberikan.

\section{Daftar Pustaka}

Anwar, Anwar. "Strategi Kolonial Belanda Dalam Menaklukkan Kerajaan Aceh Darussalam.” Jurnal Adabiya 19, no. 1 (July 17, 2020): 13. https://doi.org/10.22373/adabiya.v19i1.7482.

Anzaikhan, M. "Hakikat Administrasi Pemerintahan Islam." Al-Ijtima 'i: International Journal of Government and Social Science 5, no. 1 (October 30, 2019): 56-80. https://doi.org/10.22373/jai.v5i1.465.

- - - "Urgensi Filsafat dalam Ilmu Falak dan Relevansinya bagi Kehidupan Beragama Masyarakat." Substantia: Jurnal Ilmu-Ilmu Ushuluddin 22, no. 2 (October 30, 2020): 107. https://doi.org/10.22373/substantia.v22i2.7664.

Ariani, Iva. "Nilai Filosofis Budaya Matrilineal Di Minangkabau (Relevansinya Bagi Pengembangan Hak-Hak Perempuan Di Indonesia)." Jurnal Filsafat 25, no. 1 (August 14, 2016): 32. https://doi.org/10.22146/jf.12613.

Asmon, Rayvaldo Anggriawan, and Zakwan Adri. "Motivasi Merantau Pada Remaja Akhir Minangkabau," 2021, 7.

Dessy Asnita, Fika Andriana, Agustinar \&. "Istri Bergaji: Analisis Peran Wanita 
Bekerja Dalam Meningkatkan Ekonomi Keluarga." Al-Qadha : Jurnal Hukum Islam dan Perundang-Undangan 8, no. 1 (July 12, 2021): 13-32. https://doi.org/10.32505/qadha.v8i1.2800.

Fitriana, Yulita. "Sistem Kekerabatan Matrilineal Dalam Mitos 'Malin Kundang."” Jurnal Ilmu Budaya 15, no. 1 (November 4, 2018): 48-67. https://doi.org/10.31849/jib.v15i1.2032.

Gusti, Erwina, and Siti Aisah Ginting. "The Fading Of Hadih Maja In The Vernacular Language Among Acehnese Teenagers In Banda Aceh," 2016, 5.

Harun, Mohammad. "Revitalisasi Nilai Etos Kerja Dalam Hadih Maja Sebagai Bahan Ajar Pendidikan Karakter." Journal of Educational Science and Technology (EST) 1, no. 3 (December 14, 2015). https://doi.org/10.26858/est.v1i3.1824.

Hermaliza, Essi. "Sistem Kekerabatan Suku Bangsa Kluet Di Aceh Selatan The Kinship System Of Kluet Etnics In South Aceh," n.d., 10.

Junaidi, T, and Mufti Riyani. "Ragam Hias Aceh: Corak Identitas Dan Pemaknaannya Dalam Masyarakat Nelayan Dan Peladang,” 2017, 20.

Khalidah, Muhammad Nasir. "Penyelesaian Pembagian Warisan Di Kecamatan Simpang Ulim Dalam Perspektif Hukum Islam dan Hukum Adat." Al-Qadha : Jurnal Hukum Islam dan Perundang-Undangan 8, no. 1 (July 12, 2021): 3349. https://doi.org/10.32505/qadha.v8i1.2997.

Marta, Suci. "Konstruksi Makna Budaya Merantau Di Kalangan Mahasiswa PerantaU." Jurnal Kajian Komunikasi 2, no. 1 (2014): 17.

Munir, Misnal. "Sistem Kekerabatan Dalam Kebudayaan Minangkabau: Perspektif Aliran Filsafat Strukturalisme Jean Claude Levi-Strauss." Jurnal Filsafat 25, no. 1 (August 14, 2016): 1. https://doi.org/10.22146/jf.12612.

Mursyidin, Mursyidin, Rahmad Nuthihar, Wahdaniah Wahdaniah, and RN Herman. "Understanding Acehnese Proverbs and Their Relation to the Community Work Ethics," n.d., 6.

Nazaruddin, M. "Dimensi pembentuk kesadaran identitas keacehan dan citra diri Aceh.” Masyarakat, Kebudayaan dan Politik 27, no. 1 (January 1, 2014): 44. https://doi.org/10.20473/mkp.V27I12014.44-54.

Paisal, Jon. "Peran Dakwah Dalam Keluarga Dan Relevansinya Bagi Pembentukan Karakter Anak." Al-Qadha: Jurnal Hukum Islam dan Perundang-Undangan 8, no. 1 (July 14, 2021): 50-66. https://doi.org/10.32505/qadha.v8i1.2726.

Pohan, Muslim. "Fenomena dan Faktor Perkawinan Semarga." Al-Qadha: Jurnal Hukum Islam dan Perundang-Undangan 8, no. 1 (July 14, 2021): 67-84. https://doi.org/10.32505/qadha.v8i1.2088.

Ramanta, Helzi, and Samsuri Samsuri. "The Values of Local Wisdom of Minangkabau Culture in a Baralek Gadang Traditional Wedding." Humaniora 11, no. 3 (November 30, 2020): 193-201. 
https://doi.org/10.21512/humaniora.v11i3.6625.

Rozi, Safwan. "Negosiasi Islam Kultur Dalam Gerakan Paderi Rao Di Sumatera Tengah (1820-1833)." KALAM 6, no. 1 (February 24, 2017): 85. https://doi.org/10.24042/klm.v6i1.396.

Sidik, Humar. "Christiaan Snouck Hurgronje Dalam Dinamika Islam Di Aceh Pada Masa Kolonial Belanda." Jurnal Artefak 7, no. 1 (May 1, 2020): 31. https://doi.org/10.25157/ja.v7i1.3282.

Sovia Firdaus, Dwi Rini, Djuara P.Lubis, Djoko Susanto, and Endriatmo Soetarto. "Portrait of The Minangkabau Culture According to Hofstede's Six Cultural Dimensions." Sodality: Jurnal Sosiologi Pedesaan 6, no. 2 (September 13, 2018). https://doi.org/10.22500/sodality.v6i2.23229.

Zulfikar, Zulfikar, Adi Isworo Josef, and Ratna Endah Santoso. "Penerapan Teknik Kasab Aceh Pada Produk Sepatu Wanita Dewasa." CORAK 8, no. 2 (August 3, 2019): 113-22. https://doi.org/10.24821/corak.v8i2.2793. 